\title{
ACOUSTIC CHARACTER OF HYDRAUIIC FRACTURES IN GRANITE
}

\author{
by \\ Frederick L. Paillet \\ U. S. Geological Survey \\ Denver, Colorado
}

\begin{abstract}
Hydraulic fractures in homogeneous granitic rocks were logged with conventional acoustic-transit-time, acoustic-waveform, and acoustic-televiewer logging systems. Fractured intervals ranged in depth from 45 to $570 \mathrm{~m}$, and logs were made both before and after the fractures were induced. Unambiguous identification of almost all induced fractures was made on the three types of logs, with depth alignments verified through identification of nearby natural fractures. Most televiewer images of the induced fractures indicate the presence of discontinuous hairline fractures parallel to or splaying from the main fractures. Induced fractures also were similar in orientation to nearby natural fractures. All but the two most steeply dipping hydraulic fractures produced small apparent decreases in compressional velocity. Waveforms that propagated across hydraulic fractures at depths greater than $100 \mathrm{~m}$ had negligible shear anomalies and tube-wave attenuation. These results indicate that the hydraulic fractures at these depths were slightly open within a few centimeters or less of the borehole wall, and did not produce a measurable increase in permeability. Two induced fractures at depths of less than $100 \mathrm{~m}$ had more pronounced shear anomalies, indicating that these fractures may not have fully reclosed upon pressure release at the end of the fracture experiment.
\end{abstract}

\section{INTRODUCTION}

Acoustic waveforms have been used for many years to evaluate properties of rock adjacent to boreholes. Conventional transit-time logging techniques measure acoustic transit-time (inverse of compresslonal velocity) as a rock property directly related to primary porosity. More advanced research techniques involve simultaneous measurement of compressional and shear velocities as a means of deriving engineering properties such as Young's modulus and Poisson ratio (Cheng and Toksöz, 1981; Coates and Denoo, 1980). Other recent applications of downhole acoustic waveform logging include the use of acoustic attenuation to interpret rock quality (Stierman and Kovach, 1979; Cheng et al, 1982), to recognize the presence of natural gas in hydrocarbon reservoirs (Johnston and Toksöz, 1980), and to measure fracture permeability (Paillet and White, 1982; Paillet, 1983). At the same time, experimental data on the properties of core samples in the laboratory indicate 
that ultrasonic velocities and attenuation are a very complicated function of applied stress and saturation (Walsh, 1981; Tittman et al, 1980). The large number of unknowns in the typical borehole environment constitute a major obstacle in the application of these results to the interpretation of well-log data. The study of induced fractures decreases this uncertainty because freshly created fracture faces have not been disturbed by drilling, or altered by weathering or mineral deposition. Isolated, unpropped hydraulic fractures also should provide a test of the degree of resolution inherent in acoustic fracturedetection techniques.

\section{METHODS AND STUDY SITE}

The two wells used for this study are located in the vicinity of the Whiteshell Nuclear Research Establishment (WNRE) a few kilometers north of the Winnepeg River in eastern Manitoba, Canada (Figure 1). These wells were drilled as part of an intensive study on the hydrogeology of fractured crystalline rocks being conducted by the Atomic Energy of Canada Limited at WNRE and the nearby Underground Research Laboratory (URL). One well (designated URL1) penetrates more than $600 \mathrm{~m}$ into the granitic rocks of a batholith on the southeastern edge of the Superior Province of the Canadian Shield. The other well (designated WN4) penetrates more than $900 \mathrm{~m}$ into similar rocks of the same batholith at a location approximately $9 \mathrm{~km}$ southwest of well URL1. Both wells were completely cored to a diameter of approximately $8 \mathrm{~cm}$. This batholith was selected for study because of the homogeneous rock and few fractures observed on surface outcrops (Tammemagi et al, 1980). Configuration of fracture systems in the vicinity of the well sites, as indicated by various boreholes and surface seismic surveys, is discussed by Mair and Green (1981). Well WN4 was drilled in 1979 and logged before and after hydraulic fracturing. Well URL1 was drilled in 1981 and fractured before logging. Zones for hydraulic fracture were selected to correspond to intervals of fracture free, homogeneous rock on the basis of core inspection, televiewer logs, and other geophysical data. Both wells were drilled at an angle approximately 20 degrees from the vertical to allow gravitational orientation of core. Thirteen hydraulic fractures were induced in the wells: eight in well URL1 and five in well WN4. The wells were extensively logged with the borehole acoustic televiewer, which produces a photographic image of the borehole wall on the basis of ultrasonic reflectivity (Zemanek et al, 1969). A typical example of televiewer logs used in fracture identification is given by Keys and Sullivan (1979).

Hydraulic fractures in wells URL1 and WN4 were created by isolating selected zones with packers and increasing pressure in the packed-off zone until borehole stress concentrations produced a fracture by tension failure. Hydraulic-fracture methods for the measurement of in situ stresses are reviewed by McGarr and Gay (1978). The induced fractures studied here were created by other workers under contract to Atomic Energy of Canada Limited. The depth, observed fracture orientation on the televiewer logs, and fracture orientation corrected for hole deviation and the effects of local magnetic field inclination are listed in Table 1. 
TABLE 1-Hydraulic fractures in wells URL1 and WN4: depths are given in axial distance along borehole.

\begin{tabular}{|c|c|c|c|c|}
\hline \multirow{2}{*}{$\begin{array}{l}\text { DEPTH } \\
\text { (meters) }\end{array}$} & \multicolumn{2}{|c|}{$\begin{array}{c}\text { OBSERVED } \\
\text { ORIENTATION } \\
\text { (degrees) }\end{array}$} & \multicolumn{2}{|c|}{$\begin{array}{l}\text { CORRECTED } \\
\text { ORIENTATION } \\
\text { (degrees) }\end{array}$} \\
\hline & STRIKE & DIP & STRIKE & DIP \\
\hline \multicolumn{5}{|c|}{ WELL WN4 HYDRAULIC FRACTURES } \\
\hline 45 & N60E & 65SE & N10E & $45 \mathrm{SE}$ \\
\hline 116 & N54E & $70 S E$ & $\mathrm{~N} 7 \mathrm{E}$ & $54 \mathrm{SE}$ \\
\hline \multirow[t]{2}{*}{310} & N45E & 65SE & N12E & 44SE \\
\hline & $---m c$ & fractu & $n e-$ & \\
\hline 420 & $\mathrm{~N} 9 \mathrm{E}$ & $71 \mathrm{SW}$ & S42E & $85 S W$ \\
\hline 542 & $S 9 \mathrm{E}$ & $53 \mathrm{SW}$ & S52E & $535 W$ \\
\hline \multicolumn{5}{|c|}{ WELL URL1 HYDRAULIC FRACTURES } \\
\hline 65 & S23E & $53 \mathrm{NE}$ & S32E & $53 \mathrm{NE}$ \\
\hline 180 & N55E & 90SE & N56E & $75 \mathrm{SE}$ \\
\hline 260 & N76E & GOSE & N36E & 48SE \\
\hline 310 & $S B W$ & $50 \mathrm{SE}$ & N33E & 53SE \\
\hline 335 & $\mathrm{~N} 45 \mathrm{E}$ & $58 S W$ & N36E & $48 \mathrm{SE}$ \\
\hline \multirow[t]{2}{*}{345} & N4OE & 6OSE & N33E & 52SE \\
\hline & $-m$ & fractu & ne--.-.. & \\
\hline 376 & $\mathrm{~N} 72 \mathrm{E}$ & 5OSE & N64E & 26SE \\
\hline 570 & N73E & $43 \mathrm{SE}$ & $\mathrm{N} 6 \mathrm{BE}$ & $25 \mathrm{SE}$ \\
\hline
\end{tabular}

Acoustic-refraction data for induced and natural fractures were obtained by digitally recording the pressure signal at a receiver located approximately three acoustic wavelengths uphole from the magnetostrictive source transducer on a conventional acoustic-transit-time logging sonde (Figure 2). The source has been shown to have a relatively narrow-band output centered on 34 kilohertz ( $\mathrm{kHz}$ ) (Paillet, 1980). Waveforms were recorded using a sampling frequency of 1 microsecond $(\mu \mathrm{s})$ at depth intervals ranging from 3 to $30 \mathrm{~cm}$. Previous studies have indicated that a narrow annulus between logging tool and borehole wall results in waveforms that have well-defined shear arrivals and a simple high-amplitude pulse associated with the fundamental guided fluid mode known as the tube wave (White, 1965; Paillet and White, 1982). Amplitude logs were constructed by numerically summing acoustic energy arriving in time windows centered on tube wave and shear arrivals. Time-window results were filtered by convolution with a half-cosine function.

The only important complication in interpretation of the hydraulicfracture data for wells URL1 and WN4 consists of the large deviation of these wells from the vertical. The consistency of the corrected orientations in Table 1 indicates that the non-vertical orientation of the wells does not introduce a severe complication to the theory. The only major changes in corrected strike and dip occur within depth intervals containing the major fracture zones that were identified as regionally significant shear zones by Mair and Green (1981). For the purpose of this study it was assumed that the induced fractures represent simple, clean breaks in an otherwise homogeneous and isotropic granitic rock, and that they extend away from the borehole at approximately 
the observed orientation. The induced fractures were not artificially propped. It also was assumed that little natural propping occurred during the few cycles of small fluid volume inflation during measurement of shut-in pressures. No attempt was made to extend fractures once they had been initiated, and the use of low fluid volumes during stress measurement was assumed to have resulted in fractures that terminate in sound rock within a few meters of the borehole.

\section{ACOUSTIC-THE.EVIEWER LOGS}

All 13 induced fractures were unambiguously identified on the televiewer logs for wells URL1 and WN4; typical examples are shown in Figure 3. The first of these (Figure 3a) shows two well-defined, parallel, induced fractures in WN4 in the depth interval from 419.25 to $419.75 \mathrm{~m}$. Televiewer logs of well WN4 prior to fracturing document that the fractures in Figure 3a were not present when the well was originally drilled. The fractures dip approximately 71 degrees SE and are $25 \mathrm{~cm}$ apart. There is also a third poorly-defined fracture approximately 25 cm above the other two. The lowest fracture appears to be the most open on the televiewer log, and its width appears to have been increased by rock fragments spalling at the acute angles formed by the top and bottom of the sinusoid. Similar features have been observed on the televiewer logs of natural fractures, but it commonly had been assumed that the spalling resulted from local stress concentrations at the time when the drill bit penetrated the fracture plane. One of the two steeply-dipping induced fractures in well URL1 is shown in Figure $3 \mathrm{~b}$. This fracture appears to extend from a depth of 258 to $260 \mathrm{~m}$ (total depth not shown in the Figure) in an irregular and bifurcating trace on the televiewer log. This fracture also appears to have many of the general characteristics of induced fractures as described by Aguilera (1979). The fracture in Figure $3 \mathrm{c}$ represents the induced fracture in well URL1 with the most poorly-defined televiewer image of any of those studied. This fracture also appears to be paralleled by one or more very faint breaks within an interval of $5 \mathrm{~cm}$.

The faint, washed-out appearance of the fracture images on the televiewer logs in Figure 3 results from the convolution of a relatively broad ultrasonic pulse with a very thin fracture trace. The consistent ability to detect these fractures with the televiewer indicates, however, that the hydraulic fractures have not closed completely in the immediate vicinity of the borehole wall. The televiewer logs of almost all of the induced fractures also indicate the presence of one or more parallel fractures. These secondary fractures may indicate that failure took place along more than one parallel plane, with subsequent reopening and fracture extent localized to one of these planes. Another important qualitative feature of the induced fractures on the televiewer logs is their resemblance to natural fractures located at other depths in the same borehole. This may result from formation of naturally occurring fractures by tension failure under stress conditions similar to those at present. 


\section{ACOUSTIC-TRANSIT-TIME LOGS}

Televiewer logs for the induced fractures are compared to acoustic transit-time logs in Figure 4. All of the induced fractures except for the two steeply-dipping fractures in well URLl produced small but recognizable anomalies on the transit-time log. These exceptions apparently occur because the large interval of intersection of the fracture plane with the borehole always provides an acoustic path through unfractured rock for the source/receiver spacing illustrated in Figure 2. The transit-time anomalies for the other fractures are on about 5 to $10 \mu \mathrm{s} / \mathrm{m}$ for travel between receivers separated by approximately $30 \mathrm{~cm}$. The algorithm used in the transit time logging system determines arrival times to the nearest microsecond. The transit-time anomalies illustrated in Figure 4, therefore, appear only slightly larger than the almost random fluctuations about the nearest microsecond arrivals determined by the logging system. Such small anomalies would only be recognized in acoustic-transit-time logs for intervals of extremely homogeneous rocks. Examination of the character of first arrivals (the compressional wave) for waveforms recorded in the vicinity of the induced fractures further indicates that the small increases in transit time result from the slight lengthening of travel path required to pass behind the small opening of the induced fractures in the vicinity of the borehole wall.

\section{ACOUSTIC-TAVEFORM LOGS}

Previous analysis of acoustic-waveform anomalies associated with propagation across fractures at the study site indicated that the most consistent indicators of open fractures were tube-wave attenuation and distortion of shear arrivals (Paillet, 1980; Paillet and White, 1982). The nature of shear-amplitude distortion described in these studies was very complicated, but the most important contribution to the shear anomaly was attributed to mode-conversion effects when the acoustic energy source was located at the fracture opening. This effect appears in the amplitude logs as a pronounced increase in amplitude of the shear arrival superimposed on the delay and distortion of the shear signal produced by propagation through fractured rock. The effect on shear arrivals of propagation across one of the induced fractures is illustrated in Figure 5. This Figure compares shear arrival at the receiver with acoustic transducer located at an induced fracture and natural fracture in WN4 to shear arrivals in nearby unfractured rock. Amplitude logs constructed for the interval containing the depths for which shear waveforms are given in Figure 5 are shown in Figure 6. The qualitative similarity between the televiewer log of the induced fracture and that of the nearby natural fracture is elso indicated in Figure 6. The Figures indicate that shear anomalies associated with the induced fractures are qualitatively similar to those observed for naturally open fractures, but with smaller amplitudes. The smaller amplitudes of these shear anomalies are attributed to the closure of the induced fractures after release of the applied pressure in the packed off interval after hydraulic fracturing. If the induced fractures remain open only in the immediate vicinity of the borehole wall, then shear anomalies would be much less than in the case of natural fractures where the opening extends many acoustic wavelengths into the formation. 
The tube-wave parts of the waveforms illustrated in Figure 5 are shown in Figure 7. The complete lack of tube-wave attenuation for propagation across the induced fracture contrasts markedly with the pronounced attenuation of tube-wave amplitude for propagation across a naturally open fracture. Paillet (1980) and Paillet and White (1982) indicated that tube-wave attenuation significantly correlates with permeability for isolated fractures intersecting other wells at the study site. The lack of measurable tube-wave attenuation for propagation across the induced fractures in wells URL1 and WN4 corroborates the preceding suggestion that the induced fractures have completely reclosed except in the immediate vicinity of the borehole wall. The best explanation for the acoustic character of the induced fractures is, therefore, the complete reclosure of the induced fractures except very close to the borehole where in situ stresses have been permanently changed by the presence of the borehole. The stress-concentration field induced by the presence of an B-cm diameter borehole in a homogeneous elastic solid would exceed the ambient stress field by more than $10 \%$ in an annulus less than $5 \mathrm{~cm}$ wide according to the formula given by Timoshenko and Goodier (1951). This width is approximately one half of the $10 \mathrm{~cm}$ wavelength calculated for shear propagation at $34 \mathrm{kHz}$ in granite. If the characteristic depth of penetration for critically refracted shear waves is taken as one wavelength, then the small annulus of stress concentration can explain the relatively small shear anomalies observed in comparison with otherwise comparable natural fractures.

The two steeply-dipping fractures induced in well URL1 were virtually undetectable using acoustic-waveform logs. As in the case of compressionalwave propagation described above, this was attributed to the presence of paths through unfractured rock for all possible positions of the logging sonde in the vicinity of these fractures. Nearly vertical fractures were associated with significant tube-wave anomalies in a deep limestone petroleum reservoir (Paillet, 1981), but in that case the log response was attributed to fracture permeability. There also was an apparent increase in the relative amplitude of the shear anomalies observed for the uppermost fractures in wells URL1 and WN4. The tube wave mode was poorly excited at these shallow depths so that meaningful estimates of fracture permeability could not be made. The larger shear anomalies noted for these two relatively shallow fractures may indicate that the induced fractures were not completely reclosed at the completion of hydraulic fracturing due to the relatively small lithostatic pressure at those depths.

\section{CONCLUSIONS}

Apparently closed hydraulic fractures, with orientations varying from steeply dipping to nearly horizontal, have been consistently identifled with acoustic televiewer and acoustic-waveform logs. The only exceptions were steeply-dipping fractures in well URL1, where the geometry of fracture/borehole intersection never provided cases where compressional and shear waves were forced to cross the fracture plane. The induced fractures appear to have closed almost completely at depths below $100 \mathrm{~m}$. The complete lack of tube-wave-amplitude anomalies for these fractures corroborates that the fractures have closed, and, therefore, do not provide a significant increase in permeability. The barely recognizable compressional-transit-time and 
shear-amplitude anomalies associated with these fractures indicated that the induced fractures remained open in the immediate vicinity of the borehole wall. These slight openings in the vicinity of the borehole wall apparently do not extend more than a fraction of an acoustic wavelength into the formation, and may be related to the disturbance to the in situ stress field introduced by the presence of the borehole.

\section{ACKNOTLEDGEMENTS}

The author appreciates the cooperation of Cliff Davison, Peter Baumgardner and others from the Whiteshell Nuclear Research Establishment, Atomic Energy of Canada Limited in obtaining access to the test wells at the URL, and in obtaining background data on the hydraulic fractures. W. Scott Keys and Richard Hodges provided valuable assistance in running the televiewer logs used in this study. The Earth Resources Laboratory, Massachusetts Institute of Technology provided computational facilities and other support for some of the work performed in the preparation of this report. 


\section{REFERENCES}

Aguilera, Roberto, 1979, Naturally fractured reservoirs: Petroleum Publishing, Tulsa, Oklahoma, $703 \mathrm{p}$.

Cheng, C. H. and Toksöz, M. N., 1981, Elastic wave propagation in a fluid filled borehole and synthetic seismograms: Geophysics Vol 46, pp. 1042-1053.

Cheng, C.H. Toksöz, M.N., and Willis, M.E., 1982, Determination of in situ attenuation from full waveform acoustic logs: Journal of Geophysical Research, Vol B7, pp. 5477-5484.

Coates, G. R., and Denoo, S. A., 1980, Log derived mechanical properties and rock stress: Society of Professional Well Log Analysts, 21st Annual Logging Symposium, Lafayette, Louisiana, Proceedings, pp. U1-U11.

Johnston, D. H. and Toksöz, M. N., 1980, Ultrasonic $P$ and $S$ wave attenuation in dry and saturated rocks under pressure: Journal of Geophysical Research. Vol 85, pp. 925-936.

Keys, W. S. and Sullivan, J. K., 1979, Role of borehole geophysics in defining the physical characteristics of the Raft River geothermal reservoir, Idaho: Geophysics, Vol 44, pp. 1116-1141.

MeGarr, A., and Gay, N. C., 197B, State of stress in the earth's crust: Annual Reviews in Earth and Planetary Science, Vol 6, pp. 405-436.

Mair, J. A. and Green A. G., 1981, High resolution seismic reflection profiles reveal fracture zones within a homogeneous granite batholith: Nature, Vol 294. pp. 439-442.

Paillet, F. L., 1980, Acoustic propagation in the vicinity of fractures which intersect a fluid-filled borehole. Society of Professional Well Log Analysts 21st Annual Symposium, July 1980, Lafayette, Louisiana, Transactions, pp. DD1-DD33.

1981, A comparison of fracture characterization techniques applied to near vertical fractures in a limestone reservoir, Society of Professional Well Log Analysts 22nd Annual Symposium, June 1981, Mexico City D.F., Mexico, Transactions, pp. SS1-SS29.

1983, Acoustic characterization of fracture permeability at Chalk River, Ontario, Canada: Canadian Geotechnical Journal, Vol 20, in press.

Paillet, F. L. and White, J. E., 1982, Acoustic normal modes in the borehole and their relationship to rock properties: Geophysics, Vol 47, pp. 1215-1228.

Stierman, D. J. and Kovach, R. L., 1979, An in situ velocity study: the Stone Canyon well: Journal of Geophysical Research, Vol 84, pp. 672-6B3. 
Tammemagi, H. Y., Kerford, P. S., Requeima, J. C., and Temple, T. A., 1980, Geological and reconnaissance study of the Lac DuBonnet batholith: AECL Report 6439, $28 \mathrm{p}$.

Timoshenko, S. and Goodier, J. N., 1951, Theory of elasticity, McGraw-Hill, New York, $506 \mathrm{p}$.

Tittman, B. R., Clark, V. A. and Richardson, J. M., 1980, Possible mechanisms for seismic attenuation in rocks containing small amounts of volatiles: Journal of Geophysical Research, Vol 85, pp. 5199-5208.

Walsh, J. B., 1981, Effect of pore pressure and confining pressure on fracture permeability: International Journal of Rock Mechanics and Mining Science, Vol 1B, pp.

White, J. E., 1965, Seismic waves: transmission, radiation and attenuation: McGraw-Hill, New York, 380 p.

Zemanek, J., Caldwell, R. L., Glenn, E. E., Halcomb, S. V., Norton, L. J., and Strauss, A. J. D., 1969, The borehole televiewer: a new logging concept for fracture location and other types of borehole inspection: Journal of Petroleum Technology, Vol 21, pp. 762-774. 


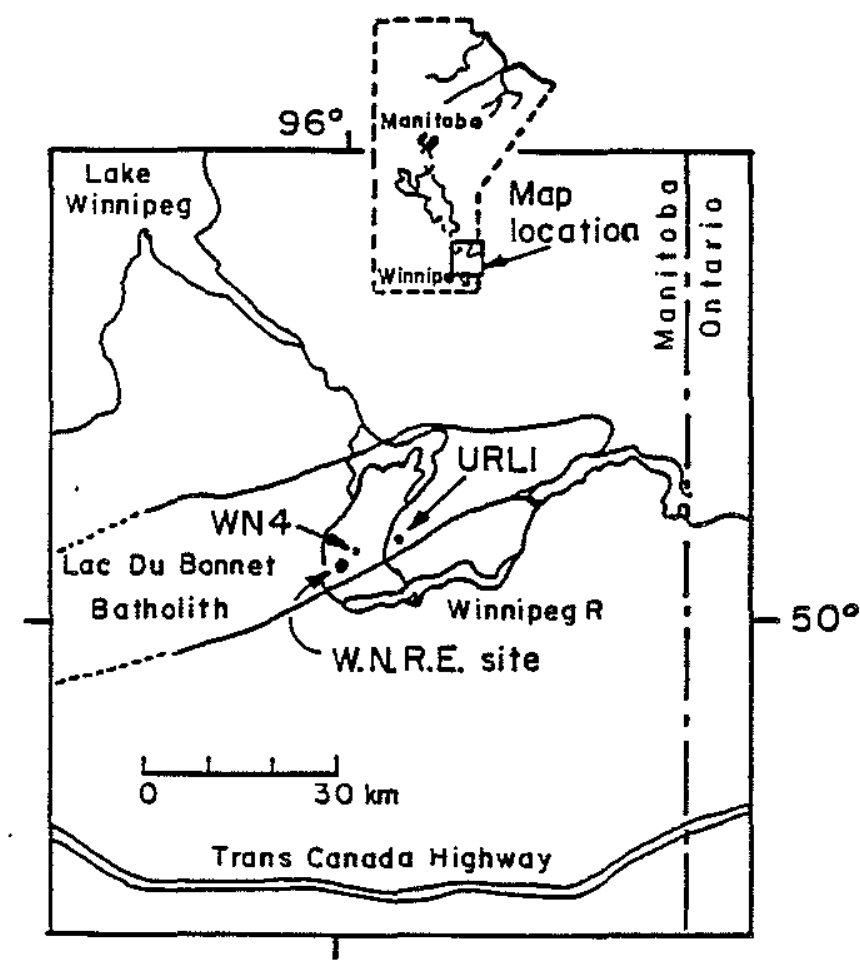

Figure 1, Location of test wells. 


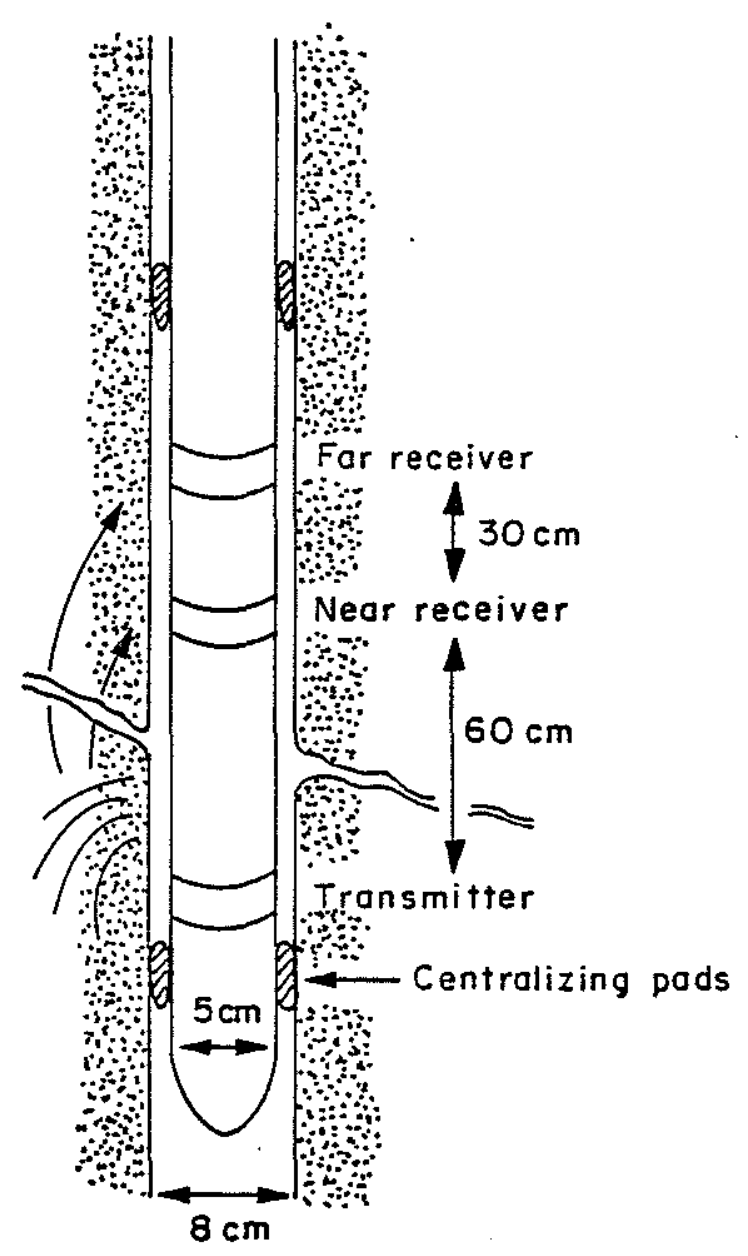

Figure 2. Schematic illustration of acoustic logging probe used for conventional acoustic transit-time and waveform logs. 

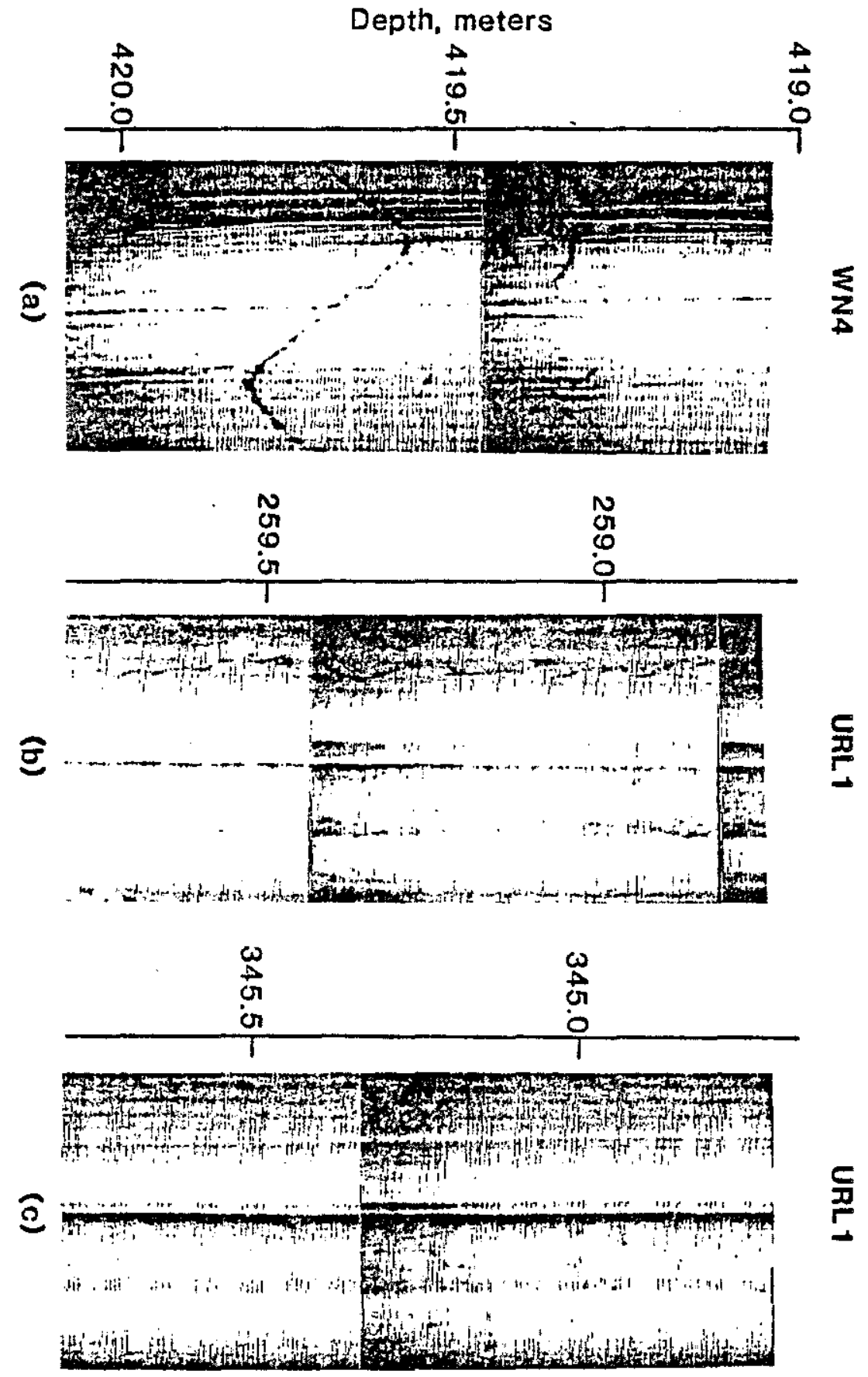

Figure 3. Representative televiewer logs of induced fractures in WN4 and URL1. 

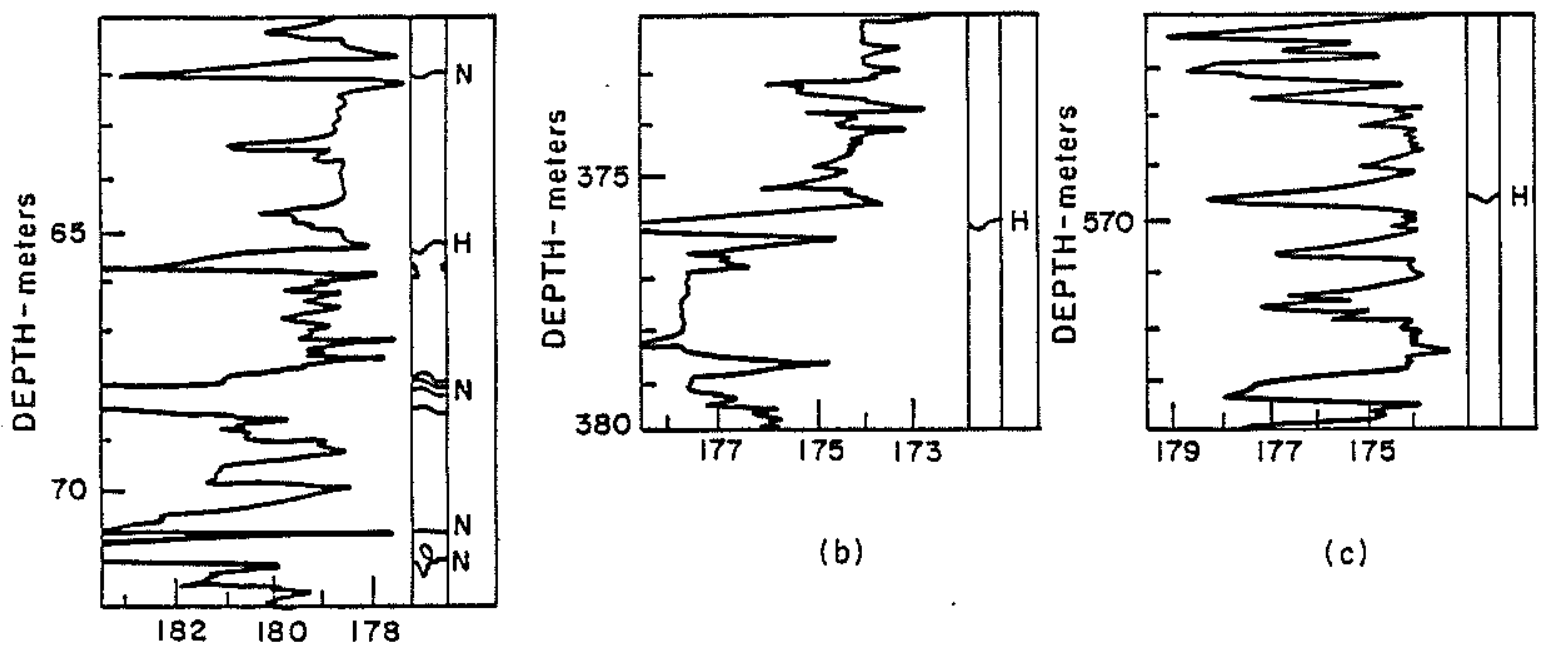

(b)

(c)

TRANSIT-TIME-microseconds

(a)

Figure 4. Depth correlation of televiewer logs with representative acoustic transit-time anomalies for examples of induced fractures; $\mathrm{H}$ and $\mathrm{N}$ indicate induced and natural fractures. 


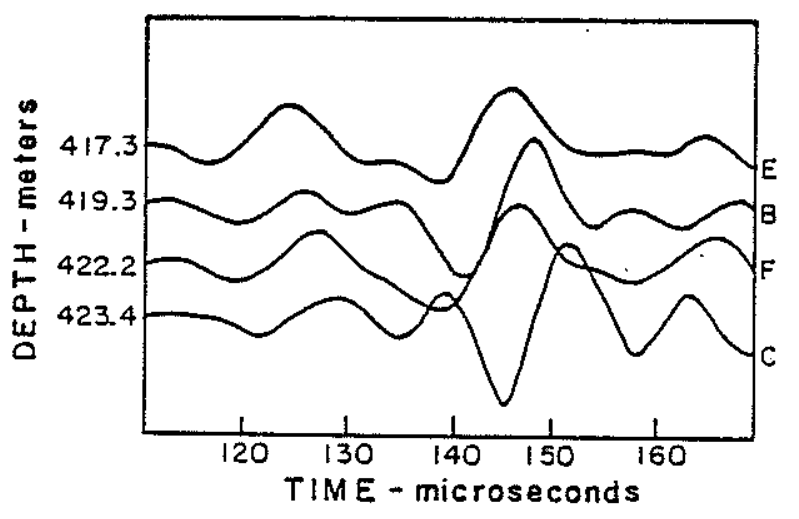

Figure 5. Character of shear arrivals for waveforms representing propagation across unfractured intervals $(E$ and $F$ ); induced fracture (B); and natural fracture $(C)$. 


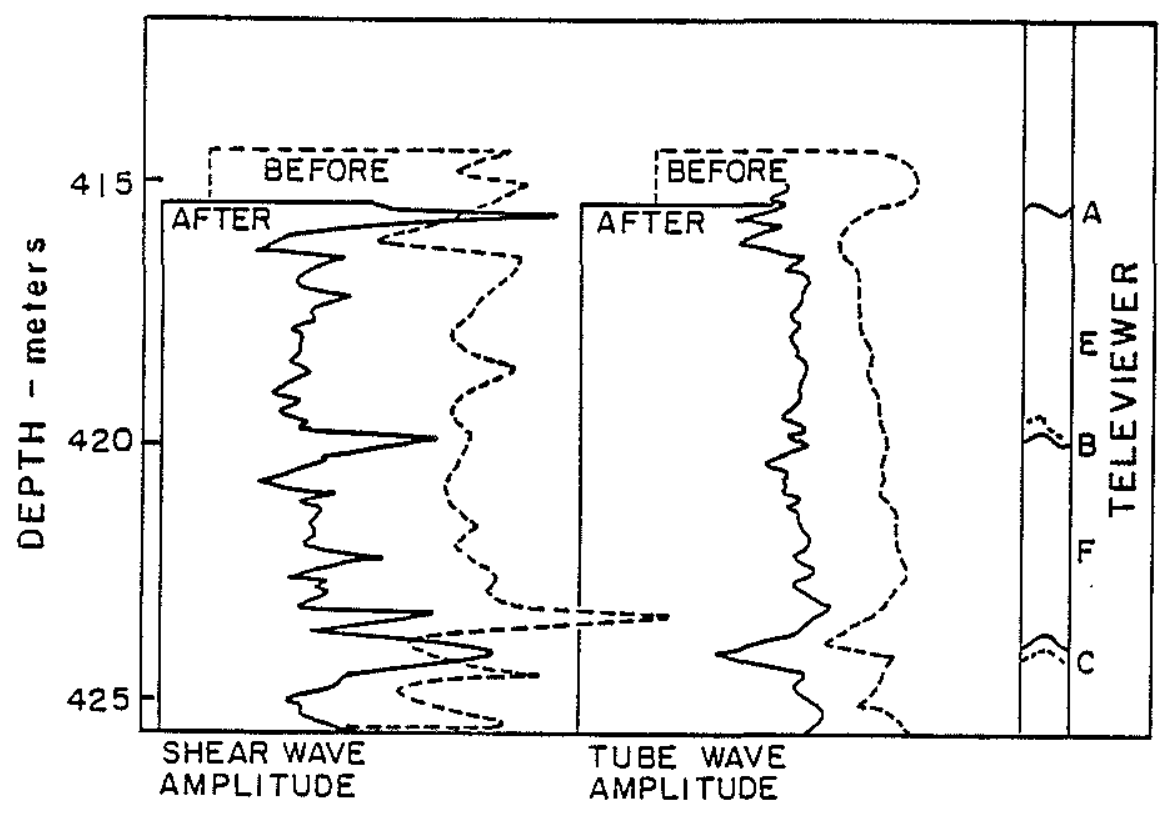

Figure 6. Shear and tube wave amplitude logs before and after hydrofracturing for interval in WN4 containing natural and induced fractures; $A$ and $C$ denote natural fractures, $B$ is the hydraulic fracture, and $E$ and $F$ denote unfractured intervals used in Figures 5 and 7. 


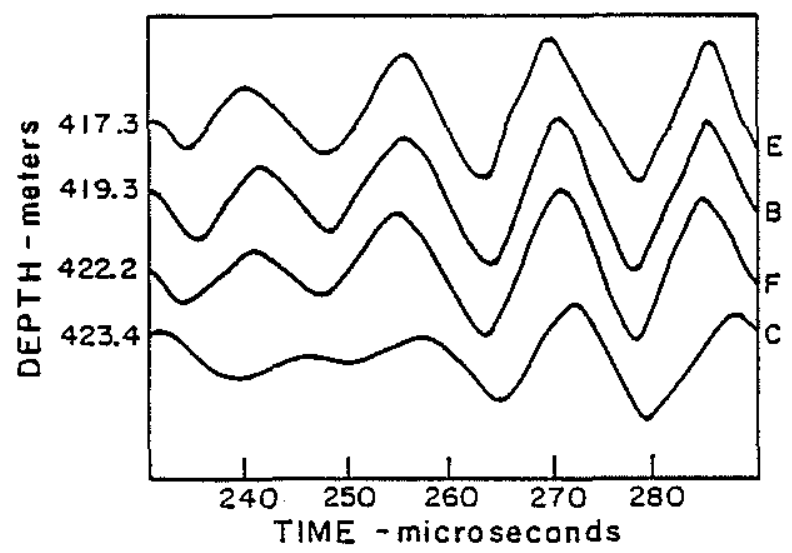

Figure 7. Character of tube wave arrivals for waveforms representing propagation across unfractured intervals $(E$ and $F)$; induced fracture $(B)$; and natural fracture (C). 